\title{
The Transformation Development Path of Local Undergraduate Universities under the Perspective of "New Engineering"
}

\author{
Zhanguo Zhang* \\ Mechanical Engineering College \\ Beihua University \\ Jilin, China \\ zzg302104@126.com
}

\author{
Yaxu Chu \\ Dean's Office \\ Beihua University \\ Jilin, China \\ 657352690@qq.com
}

\begin{abstract}
Guiding partial local undergraduate universities to transform into the applied ones is a major decision made by the CPC central committee and the state council. Under the perspective of "new engineering", this paper focused on the five important areas including adjusting specialty structure, innovating talent training mode, optimizing talent training program, reforming teaching methods, constructing teaching staff and deepened the education and teaching reform leading by industries, basing on the school-running orientation of local undergraduate universities. Which have done promote the closed abutting joint between the talent training of local undergraduate universities and the regional economic and social development, and improve the specialty construction level based on the new requirement and new challenge from the new era.
\end{abstract}

Keywords—path; transformation development; local undergraduate university; new engineering

\section{INTRODUCTION}

In October 2015, Ministry of Education, National Development and Reform Commission and Ministry of Finance of the People's Republic of China jointly issued the guidance on guiding partial local undergraduate universities to transform into the applied ones, which meant that China would set about constructing the classification system of colleges and universities in order to form a clearly positioning, scientific, and reasonable higher education eco-structure. At present, new economy represented by new technology, new format, new industry and new business model is advancing vibrantly, which puts forwards higher requirement for engineering talents [1], so as to urgently need to accelerate the "new engineering" construction and development. Since 2017, Ministry of Education has actively promoted the "new engineering" construction, and formed a series of policy documents, such as "Fudan University consensus", "Tianjin University action” and "Beijing guide", to be committed to exploring and forming the

The research was financially supported by 2016 year's major project on teaching reform of higher education for undergraduate in Jilin province "Research and Practice on Transformation Development Path and Talent Training Mode of Mechanical specialty Clusters" (Project Number: SGJY201613), by 2017 year's general project on education science planning by Jilin province in the 13th Five-Year period "Research on " $3+1$, Preemployment" Mode That school and enterprise Jointly Train Applied Mechanical Talents" (Project Number: GH170081), and by 2017 year's general project on teaching reform of vocational education and adult education "Research on Transformation Path of Specialty Clusters in Local Undergraduate Universities” (Project Number: 2017ZCY112).
Chinese model and Chinese experience that can lead global engineering education.

\section{Determining Transformation Development Path}

To train the applied talents and service for the regional economic and social development are emphasized in local undergraduate universities is driven by the deepening of higher education popularizing process, more fundamentally is driven by the economic and social development, especially is driven by the new economic development. So local undergraduate universities should look for the power source of transformation development from regional industrial reform and economic and social development, and should look for the transformation development path combining with the law of market economy, talents' growth, production and dissemination of modern knowledge. Now, China's economic development is turning to innovation-driven, new a round of scientific and technological revolution is promoting profound changes of industries, the development mode, production mode, organization mode of industries and the sale mode of products are all changing. Local undergraduate universities should research and practice on the five aspects of transformation including specialty structure, talent training mode, talent training program, teaching methods and teaching staff, and deepen industry-education integration, school-enterprise cooperation and cooperative education, basing on the background of new technology, new industry and new economy, and closely surrounding the three basis points of localization, applied-type and serviceability. So as to set up the "new concept" of engineering education with innovation type, synthesis and whole cycle [2], to construct the "new structure" of discipline and specialty that the emerging engineering and traditional engineering are combined, to explore the "new mode" of talent training, to forge the "new quality" with international competitiveness. The ultimate goal is to train a large number of new-type engineering talents with the stronger ability to adapt to changes and engineering innovation ability.

\section{CONSTRUCTING THE "NEW STRUCTURE" OF ENGINEERING SPECIALTY}

China's economic development is entering the crucial period of structural adjustment, transformation and upgrading, the new growth drivers are taking place of the old ones, and a new round of technological and industrial revolution centering 
on the internet is poised to take place. Engineering education and industries closely connect and support each other; the development of new industries must be supported by talents provided by engineering education. To meet the challenges of international competition in new technologies and new industries in the future, local undergraduate universities must actively arrange the training of engineering talents, accelerate the construction and development of emerging engineering specialties, and reconstruct and upgrade traditional engineering specialties, so as to improve the ability that engineering education supports and services for industry development.

Local undergraduate universities should promote the adapting discipline and specialty construction to industrial transformation and upgrading, and construct the discipline and specialty system that closely docks with industrial chain and innovation chain by shifting from discipline-oriented to industry-demand-oriented, from specialty segmenting to multispecialty merging and boundary crossing, from adaptation and service to support and guide [3]. Specialty structure can be adjusted through combination, reconstruction, elimination or addition. Then the specialty clusters with discipline chain inside and industry chain outside can be constructed by establishing the backbone discipline of specialties and the service orient of industries based on multi-disciplinary merging and whole industry chain. Which the specialty clusters develop, compound and cross coordinately will promote the healthy development of relative specialty education.

\section{A. Setting up and Developing Emerging Engineering Specialties}

According to the development trend of new technology and new industry, local undergraduate universities should set up a batch of emerging engineering specialties that service for the development of local pillar industries and strategic emerging industries, should forge specialty clusters that service for the emerging industries. The emerging engineering specialties such as robotics engineering, data science and big data technology, big data management and application, internet of things engineering, etc., should be added so as to speed up training the extremely scarce and urgently needed talents in our country.

\section{B. Reconstructing and Upgrading Traditional Engineering Specialties}

Merging the new technologies such as internet, cloud computing and big data, etc., traditional engineering specialties should be reconstructed with digitization, networking and intellectualization, so as to improve the ability that specialties service for industrial transformation and upgrading. Local undergraduate universities also should promote intercrossing and merging between the existing engineering disciplines, engineering disciplines and other disciplines, promote applied sciences to extend to engineering disciplines, so as to gestate and format the emerging interdisciplinary specialties such as intelligent manufacturing engineering, intelligent medicine engineering, microelectronics science and engineering, photoelectric information science and engineering, etc. Local undergraduate universities must avoid putting old wine into new bottles in the process of reconstructing and upgrading the traditional engineering specialties, the "new engineering" construction proposes putting new wine into old bottles.

\section{INNOVATING TALENT TRAINING MODE}

On the basis of summarizing and referring to the reform experience of talent training mode of engineering education such as "The Program for Educating and Training Outstanding Engineers”, “CDIO (Conceive, Design, Implement, Operate)”, etc., local undergraduate universities should deepen the reformation of talent training mode of "combination of production, education and research, integration of teaching, learning and doing", so as to set up the talent training process of developing the ability to adapt to changes, to practice in engineering and to innovate as the lead.

\section{A. Setting up the Engineering Education Concept of Synthesis} and Whole Cycle, Implementing the Requirements of "CDIO" and "OBE (Outcome-Based Education)" and

Designing Multi-level and Multi-stage Practice Links

Local undergraduate universities should build the new platform for practical teaching, referring to the engineering education concept of "CDIO", basing on the thinking "abilityoriented of whole industry chain". Then, taking the whole life cycle of product of conceive, design, implement and operate as the carrier, deeply implement the cooperative education mode of "industry-education integration, science and education combination, school-enterprise cooperation", establish the teaching chain successively running through theory learning, hands-on practice, inquirylearning to make design activities appear throughout the whole process of practice teaching. To do so, the crossing spiral theory teaching and practice teaching will be implemented, students' practice ability training will be continuous. Also will make students get significative integrated design experience and will form the comprehensive quality and engineering ability that future engineers should have through initiative practice and learning by doing [4].

Local undergraduate universities should absorb the funds, donating and relevant resources from society and enterprises, co-construct the specialty teaching platforms such as practice base, joint laboratory, so as to build "new engineering" talent training highland together. Then, carry out the specialty practice ability training measures in the form of "platform plus project plus team", supported by platform, led by project and propped by team. Taking the classroom teaching, experimental teaching, engineering practice and innovative practice as the carrier, a new system for training the innovative talents with the characteristics of project, systematization, coordination and diversification can be constructed, through the combination of theory teaching and practice teaching, the combination of oncampus experiment and off-campus practice and the combination of scientific research and extracurricular scientific and technological activities.

\section{B. Setting up the Engineering Education Concept of Innovation-Type and Integrating Innovation and Entrepreneurship Education into the Whole Process of Specialty Education}

Local undergraduate universities should further implement the specific requirements of innovation and entrepreneurship education of engineering specialties, perfect the "originalityinnovation-entrepreneurship" education system, build the wide platform for innovation and entrepreneurship practice 
such as business incubator, technology entrepreneurship practice base and hacker space, etc., create the innovation and entrepreneurship education campus atmosphere. Moreover, local undergraduate universities should extensively implement the innovation and entrepreneurship practice activities to try to make over $50 \%$ engineering students participate in "The Undergraduate Innovation and Entrepreneurship Training Program" or an innovation and entrepreneurship competition. To do so, can promote innovation and entrepreneurship education to run through in all side and integrate into deeply specialty education, can focus on training student's innovation spirit, enterprise consciousness and creative ability.

\section{Adhering to the Specialty Construction Concept of "OBE" and Promoting Engineering Education Specialty \\ Certification}

Local undergraduate universities should deepen education and teaching reform, adhere to and implement the engineering education specialty certification concepts of "student-centered, outcomes-based, continual improvement", basing on the specialty certification bottom line, complying with the specialty certification standards. And focus on the graduates' communicational ability, cooperative ability, specialized knowledge and skills, life-long learning ability, sound worldview and strong sense of responsibility to continuously improve the talent training quality, to promote specialty construction to connect with international engineering education quality standards, ultimately to achieve the effective equivalence of engineering education talent training quality between local undergraduate universities of China and all member countries of the "Washington Accord".

\section{OPTIMIZING TALENT TRAINING PROGRAM}

Local undergraduate universities should optimize talent training program on the basis of the industry and enterprise needs and post requirements, referring to the national standards, industrial standards and international standards. At the same time, should drive curriculum reform by social and economic development, industrial technology progress, integrate the theoretical curriculums, experimental curriculum and practical curriculum, aiming to construct the training objective facing internal and external demands, the training standard facing learning outcomes, the curriculum system facing ability achieved, the course content facing achievable measure, the evaluation mechanism facing continuous improvement. Also, should respect students' individualized choice and provide individualized training path. Furthermore, the talent training program must be drew up by full society investigation and demonstration, its forming process requires the industry and enterprise personnel to participate, so as to meet the quality and ability requirement of engineering talent for the vigorous development of new economy.

\section{A. Referring to Domestic and Overseas Mainstream \\ Engineering Education Standards and Establishing the Ability System of Future Engineering Talent}

Fully introducing and implementing the education concepts of "CDIO" and "OBE", referring to "The National Quality Standards of Undergraduate Specialties of Ordinary Universities and Colleges", the general standards for "The
Program for Educating and Training Outstanding Engineers”, the relevant industry standards and specialty certification standards of engineering education, local undergraduate universities should analyze the humanistic quality, scientific quality, engineering quality and professional quality of future engineering talents should have, establish the knowledge and ability system in key fields such as the engineering technology, information technology, economic management, law and culture of engineering talents should have, take promoting the comprehensive development of human beings and adapting to the needs of society as the fundamental standard of measuring the level of talent training [5], and focus on training students' social responsibility to serve country and people, innovative spirit for exploration and practical ability to solve problem.

\section{B. Constructing Modular Curriculum System According to the Engineering Logic}

Orienting by the social needs, with practical engineering as the background, with engineering technology as the main line, with strengthening students' engineering practice ability, engineering design ability and engineering innovation ability as the core, local undergraduate universities should carry out the learning outcomes-oriented curriculum system reconstruction by breaking the interdisciplinary boundary and teasing out the knowledge points of main courses. So as to establish the one-to-one corresponding relationship between ability achieved and curriculum system and construct the integrated curriculum system following the engineering logic and education law [6]. Moreover, local undergraduate universities should construct curriculum system integrating theory and practice, optimize curriculum structure, integrate course content following technical development, so as to form course group or course module that highlighting training practical ability. Particularly, the practical teaching system integrating in-class links and extracurricular activities should be established, the proportion of training and practice classperiods in the total class-periods of curriculum teaching should be more than $30 \%$. The links of experiment, training and practice should be strengthened and the quality assurance mechanism for training and practice should be established, to enable students to learn the knowledge of specialty field with interest, research and practice, and to increase engineering practice ability, innovation ability and scientific research ability gradually and systematically [6].

\section{REFORMING TEACHING AND ASSESSMENT METHODS}

One of the important goals of university course teaching is to cultivate students' questioning spirit and critical thinking, and it mainly depends on the teaching methods adopted by the course. Teacher and student are the two main subjects in education and teaching, and the deep interaction between the subjects is the fundamental to improve teaching quality. In teaching reform, local undergraduate universities should transform the traditional and passive cramming learning mode into the active and collaborative inquiry learning mode, really change from teacher-centeredness to student-centeredness and take the achievement of training goal as the core standard of teaching evaluation, so as to highlighting the training of students' innovation potential, engineering practice ability, 
ability to analyze and solve complex engineering problems and comprehensive ability to carry out engineering research.

\section{A. Promoting the Revolution in Teaching Methods}

In classroom teaching, the "feeding" learning mode should be changed; the interaction between teachers and students should be enhanced so that the present "phubbing" class can be truly transformed into the "strong interaction" class. Local undergraduate universities should actively popularize the student-centered and teacher-led small-class teaching, case teaching, project teaching, situational teaching and workprocess-oriented teaching, etc., so as to fully stimulate students' learning interest and enthusiasm. Also, local undergraduate universities should promote the deep integration of modern information technology and education and teaching, construct and use open online courses, so as to integrate the offline and online space, stimulate students' learning motivation, to make students grasp the learning initiative and control the learning content and progress, to facilitate students' cross-disciplinary learning and meet students' diverse learning needs.

While teaching, theoretical learning, practical application, problem solving and project management should be integrated, stick to the work-learning combination and industry-education integration. Teachers teach in doing, also students learn in doing which can achieve the mutual connection between the teaching process and the production process, and realize the training of students' higher ability. Also local undergraduate universities should make full use of the technologies such as virtual reality, digital simulation, etc., to innovate the teaching methods of engineering practice.

\section{B. Reform Students' Assessment Methods}

Local undergraduate universities should carry out the diversified assessment methods to change the final assessment into the process assessment, the one assessment into many assessments, the closed assessment into the open assessment, and the school assessment into the school-enterprise joint assessment [7]. The written test, oral test, non-standard answer test and other forms should be comprehensively applied, so as to completely examine students' mastery and application of knowledge, to realize promoting learning by examination, assisting teaching by examination, and to continuously improve the teaching quality.

\section{Constructing the "Double-QUALIFIED” teAching STAFF}

Only by strengthening the construction of the "doublequalified" teaching staff and the improvement and transformation of the teachers' overall teaching ability, and breaking through the bottleneck of the teachers' knowledge structure and practical teaching ability, can local undergraduate universities realize the transformation to applied one in the true sense.

Local undergraduate universities should set up the teachers' teaching development center which is specifically responsible for the cultivating and training teachers. According to the objectives and requirements of talent training, the center should perfect the cultivating and training system for teachers and comprehensively carry out the training of teachers' teaching ability. In order to improve the integral practice teaching level, research and development ability of applied technology of the specialized teachers, local undergraduate universities should designedly send teachers to enterprises for training, working and practicing. On the other hand, local undergraduate universities should actively introduce the recognized professionals of industries; recruit the excellent professional and technical talents, managerial talents and high-skilled talents as the academic leaders, the full-time or part-time teachers [8]. In these ways, a "double-qualified" teaching staff with the qualifications such as teacher and engineer and with the ability such as teaching and practice will be gradually built up [9].

\section{CONCLUSION}

Transforming into the applied type is the new mission and road of local undergraduate universities, and new achievements will be made. The transformation development of local undergraduate universities must insist on the guidance of the Scientific Outlook on Development, fully implement the party's education policy. By clarifying the school-running orientation, refining the school-running characteristics, transforming the school-running ways, really turn the school-running ideas of local undergraduate universities to servicing for the local economic and social development, to industry-education integration and school-enterprise cooperation, to training applied talents, to enhancing students' employability and entrepreneurial ability, so as to comprehensively improve the ability of universities to service for regional economic and social development and innovation-driven development [10].

\section{REFERENCES}

[1] Li Qiquan, Li Hong, "Study on the engineering culture education in construction of "new engineering”", Journal of Anhui Jianzhu University, vol. 25, pp. 79-82, August 2017. (In Chinese)

[2] Wang Fujun, Lu Suhua, "Research on the specialty construction of local applied university from the perspective of "new engineering”, , Popular Science (Science Education), pp. 148-149, September 2017. (In Chinese)

[3] Jiang Zongli, "The computer-related specialty reform under the background of new engineering construction", China University Teaching, pp. 34-39, August 2017. (In Chinese)

[4] Wu Aihua, Hou Yongfeng, Yang Qiubo, etc., “Accelerating development and construction of emerging engineering, taking in itiative to adapt to and lead the new economy”, Research in Higher Education of Engineering, pp. 1-9, January 2017. (In Chinese)

[5] Wang Long, Cheng Jun, “On improving the talent training quality of higher education”, Journal of Changchun Education Institute, vol. 30, pp. 123-124, June 2014. (In Chinese)

[6] Xu Yang, Wang Hongbo, Gao Weidong, etc., "Constructing undergraduate innovative training system, improving the quality of talent training”, University Education, pp. 60-61, January 2013. (In Chinese)

[7] Ding Chikun, Tang Shuhong, Li Qiang, etc., "Research on the transformation development program of physics specialty in applied university”, The Guide of Science \& Education, pp. 20-21, September 2017. (In Chinese)

[8] Han Dina, "Study on the construction of part-time art teachers in local universities — taking music performance specialty as the example”, New West, pp. 112, June 2016. (In Chinese)

[9] Yang Fei, Yao Ye, Zhang Weiqin, etc., "Some suggestions on the improvement of teaching ability of teachers in local universities 
under the background of transformation”, China Education of Light Industry, pp. 20-22, October 2016. (In Chinese)
[10] He Zhiji, “Thoughts on "Double Tops” construction which local universities link the state”, Application-Oriented Higher Education Research, vol. 1, pp. 8-11, December 2016. (In Chinese) 